\title{
Políticas públicas no assentamento Mãe Maria em São Félix do Araguaia - MT
}

\author{
Public policies in the Mãe Maria settlement in São Félix do Araguaia - MT
}

Joelma Alves Barbosa ${ }^{1}$ (D), Polyana Rafaela Ramos ${ }^{2}$ (D), André Alves Barbosa ${ }^{3}$ (D)

Recebido em 19 de novembro de 2020 | Aprovado em 08 de janeiro de 2021

\begin{abstract}
RESUMO
As políticas públicas são serviços fundamentais no processo de desenvolvimento da agricultura familiar. Desta maneira o objetivo deste trabalho foi conhecer a realidade desses sujeitos frente a atuação da ATER no projeto de Assentamento (PA) Mãe Maria no município de São Félix do Araguaia - MT. Foi realizado uma pesquisa quali-quantitativa utilizando a técnica da entrevista, por meio da aplicação de um questionário semiestruturado com perguntas dissertativas e objetivas, abrangendo cerca de $30 \%$ dos assentados. No trabalho foram abordados assuntos ligados às questões socioeconômicas e logo após o que diz respeito a percepção e dificuldades com relação a política de ATER pelos agricultores do PA. Após a coleta dos dados fez-se a transcrição para uma planilha do Excel e realizado as análises pertinentes. Dos entrevistados, cerca de $62 \%$ afirmaram nunca ter recebido assistência técnica e $36 \%$ relataram não ter conhecimento desses programas. Dos que receberam algum tipo de serviços de ATER, 71\% argumentaram ter obtido resultado eficaz em mais de $90 \%$ das atividades realizadas. Deste modo, foi possível observar que há uma carência dos serviços da ATER para os assentados do PA Mãe Maria, implicando diretamente nos resultados obtidos nas propriedades.
\end{abstract}

Palavras-chave: Segmento familiar; Desenvolvimento; Assistência rural.

\begin{abstract}
Public policies are fundamental services in the development process of family farming. Thus, the objective of this work was to know the reality subject to ATER's performance in the Mãe Maria Settlement (PA) project in the municipality of São Félix do Araguaia - MT. A qualitative-quantitative research was carried out using an interview technique, through the application of a semi-structured questionnaire with essay and objective questions, covering about $30 \%$ of the settlers. In the work, issues related to socioeconomic issues were resolved, and soon after, what concerns the perception and difficulties in relation to the ATER policy by farmers in the PA. Data collection was transcribed to an Excel spreadsheet and performed

\footnotetext{
${ }^{1}$ Graduanda em Agronomia pelo Instituto Federal de Educação, Ciência e Tecnologia de Mato Grosso (IFMTCampus Confresa). Endereço para correspondência: Rua MN4, S/N, Setor Morada Nova, Confresa, MT, Brasil. CEP: 78652-000. E-mail: joelma.barbosa.ifmt@mail.com.

${ }^{2}$ Mestre em Ciências Ambientais pela Universidade do Estado de Mato Grosso (UNEMAT - Campus Cáceres). Professora no Instituto Federal de Educação, Ciência e Tecnologia de Mato Grosso (IFMT-Campus Confresa). Confresa-MT-Brasil. Endereço para correspondência: Av. Vilmar Fernandes, número: 300, Setor Santa Luzia, Confresa, MT, Brasil. CEP: 78652-000. E-mail: Polyana.ramos@cfs.ifmt.edu.br.

${ }^{3}$ Mestre em Ciências Agrárias pelo Instituto Federal de Educação, Ciência e Tecnologia Goiano (IFGOIANO Campus Rio Verde), Rio Verde-GO. Endereço para correspondência: Av. Ariosto da Riva, 377, Setor Mãe Maria, Alto Boa Vista, MT, Brasil, CEP: 78665-000. E-mail: andre.barbosa.agro@ outlook.com.
} 
the relevant ones. Of those interviewed, about $62 \%$ said they never had a technical request and $36 \%$ reported not having knowledge of these programs. Of those who received some type of ATER services, $71 \%$ claimed to have been effective in more than $90 \%$ of the activities carried out. In this way, it was possible to observe that there is a lack of ATER services for the PA Mãe Maria settlers, directly implicating the results obtained in the properties.

Keywords: Family segment; Development; Rural assistance.

\section{Introdução}

A agricultura familiar tem se destacado ao longo dos anos no agronegócio, no entanto, depende de um processo contínuo de fortalecimento e valorização por meio de fatores que englobem razões sociais, culturais, políticas e econômicas (ARRUDA; ARAUJO, 2019). O reconhecimento da atividade familiar como um segmento socioprodutivo nos últimos anos, permitiu o desenvolvimento de diversas políticas públicas voltadas as suas atividades, favorecendo seu desenvolvimento social, econômico e cultural.

No estado de Mato Grosso, a agricultura familiar é extremamente relevante, uma vez que mais de $90 \%$ dos agricultores exploram atividades como: a mandiocultura, fruticultura e pecuária de leite. No entanto, os produtores familiares apresentam dificuldades para alcançar uma escala mínima de produção, devido às limitações na capacidade de investimento, falta de assistência técnica e dificuldades para acessar às novas tecnologias de modo a ampliar sua produtividade (FERRO; VECHI, 2014).

Nesse sentido, para fortalecer a agricultura familiar, são necessárias políticas públicas, com destaque para a Assistência Técnica e Extensão Rural (ATER) que embora tenha seu marco registrado no país desde o final da década de quarenta do século $\mathrm{XX}$, com a criação da Associação de Crédito e Assistência Rural (ACAR) no estado de Minas Gerais (CASTRO; PEREIRA, 2017), atualmente, encontra-se difundida em todo o território nacional, conhecida neste momento como Política Nacional de Assistência técnica e Extensão Rural (PNATER), estabelecida pela lei n. ${ }^{\circ} 12.188$ de 11 de janeiro de 2010 (BRASIL, 2010). Essa política é fundamental no processo de desenvolvimento rural e da atividade agropecuária, sendo um instrumento de mediação de conhecimento e de transferência de novas tecnologias geradas por meio da pesquisa, e outros conhecimentos (SILVA, 2016).

O autor afirma que a "ATER são serviços fundamentais no processo de desenvolvimento rural e da atividade agropecuária, pois é um instrumento de comunicação de conhecimento de novas tecnologias, geradas pela pesquisa, e outros conhecimentos".

Para Queiroz; Costa (2015), a PNATER tem como propósito a melhoria nas condições de vida da população rural, apoiando o processo de modernização da agricultura familiar e 
inserindo às em estratégias voltadas à política do país. Ainda em conformidade com os autores, contribui para a promoção do desenvolvimento rural sustentável, com destaque para o processo de desenvolvimento, apoiando os agricultores familiares, na potencialização do uso sustentável dos recursos naturais.

De acordo com Laforga e Vieira (2008) a PNATER é uma política no qual visa orientar órgãos e agências responsáveis por oferecer serviços de ATER nas propriedades familiares. No estado de Mato Grosso a Empresa Mato-grossense de Pesquisa, Assistência e Extensão Rural (EMPAER) é a principal responsável por levar ATER aos pequenos e médios agricultores, atuando em 127 municípios, atendendo mais de 40 mil produtores.

"As dificuldades ainda vivenciadas pelo agricultor familiar no meio rural brasileiro reafirmam a importância da extensão, estimulando a atualidade do debate em torno das políticas de ATER tanto nas universidades, como em órgãos públicos, privados e ONGs" (SANTOS et al., 2018).

Nesse contexto, o trabalho tem por objetivo diagnosticar os principais desafios encontrados pelos agricultores familiares no Projeto de Assentamento (PA) Mãe Maria, localizado no município de São Félix do Araguaia no estado de Mato Grosso, tendo base o percentual de famílias beneficiárias ou não dos programas de ATER.

\section{Metodologia}

O município de São Félix do Araguaia está localizado na região Araguaia Xingu no Nordeste do estado, ocupando uma área de $16.713,475 \mathrm{~km}^{2}$, composto por uma população estimada em 11.708 habitantes, com densidade demográfica de 0,64 hab. $/ \mathrm{km}^{2}$, sendo que destes, 4.447 vivem no meio rural (Instituo Brasileiro de Geografia e Estatística - IBGE, 2017).

A pesquisa foi desenvolvida durante os meses de julho a novembro de 2019 no Projeto de Assentamento (PA) Mãe Maria, situado no município de São Félix do Araguaia a 1.143 km de Cuiabá no estado de Mato Grosso.

Esse município possui dez PAs da Reforma Agrária em uma extensão 135.216,00 hectares (ha). Dentre eles, está localizado o PA Mãe Maria, criado em 16 de março de 1999, destacando por sua capacidade ocupacional, contando com 485 famílias assentadas em uma extensão de 24858,8 km² (Instituto Nacional de Colonização e Reforma Agrária - INCRA, 2017). 
A economia do município se concentra basicamente na atividade pecuária com maior ênfase na criação de gado de corte e leiteiro, justificado pelas facilidades nos tratos culturais e fácil inserção no mercado consumidor da região.

No levantamento de dados para a pesquisa, fez-se o uso da metodologia qualiquantitativa, utilizando o método de entrevista por meio de um questionário semiestruturado com perguntas abertas e fechadas, abordando assuntos relacionados às questões socioeconômicas, atividades desenvolvidas na propriedade, assim como as dificuldades enfrentadas, a percepção e conhecimento do produtor no que diz respeito aos serviços prestados pela Assistência Técnica e Extensão Rural (ATER).

De acordo com Bianquini et al. (2010), o método qualitativo complementa o método quantitativo, uma vez que o primeiro é mais profundo e possibilita um conhecimento detalhado e o segundo possibilita verificar o maior número de pessoas e se os apontamentos obtidos no primeiro são coerentes.

As entrevistas foram realizadas durante os meses de julho a novembro de 2019 a uma amostra de 132 dos 485 agricultores residentes no PA. No universo da pesquisa optou-se por investigar os sujeitos sem restrição de sexo e com idade a partir dos 18 anos, dando preferência aos residentes da família com melhor desenvoltura na comunicação para respondê-las.

É importante destacar que a escolha do uso de perguntas abertas foi a fim de obter a real percepção dos agricultores por meio de suas afirmações e justificativas referente ao conhecimento, definição e atuação da ATER enquanto política pública; possíveis razões para a carência desta política no assentamento e como a ATER melhoraria a qualidade na vida destes produtores.

Após o levantamento de campo, fez-se a tabulação dos dados utilizando a planilha de dados e em seguida, feito as análises pertinentes.

\section{Resultados e discussão}

3.1 Perfil socioeconômico dos agricultores familiares do PA Mãe Maria no município de São Félix do Araguaia-MT

O assentamento PA Mãe Maria tem 485 famílias, das quais 132 foram entrevistadas. Destas $56,81 \%$ (Figura 01) tem idade superior a 50 anos e apenas $0,75 \%$ têm idade menor que trinta anos. Esse dado é um fator preocupante, devido a evasão dos jovens do meio rural, fato 
que poderá ocasionar problemas, como a sucessão rural. Esses dados corroboram com apresentados por (ZÓTIS, 2011). Para garantir a permanência do jovem no campo é necessário criar políticas públicas especificas, tais como as políticas de incentivos ao empreendedorismo local (ALBUQUERQUE, 2014).

O tamanho das propriedades no assentamento era semelhante, com aproximadamente 50 ha, uma vez que foi o INCRA (Instituto Nacional de Colonização e Reforma Agrária) que determinou a quantidade de área para cada indivíduo. A faixa etária dos pesquisados variam dentre 18 e 80 anos, conforme pode ser observado na figura 01 , sendo possível averiguar que cerca de $56,81 \%$ dos indivíduos têm idade superior a 50 anos e somente $0,75 \%$ possuem idade inferior a 30 anos. Dados semelhantes foram encontrados por Barbosa (2017), no PA Independente I no município de Confresa - MT, em que há predominância de agricultores com faixa etária entre 50 e 60 anos representa um percentual de 32,81\% do total de entrevistados, sendo que 40,63\% vivem há mais de 20 anos na propriedade.

Figura 01 - Faixa etária dos produtores rurais do assentamento Mãe Maria. São Félix do Araguaia-MT, 2019.

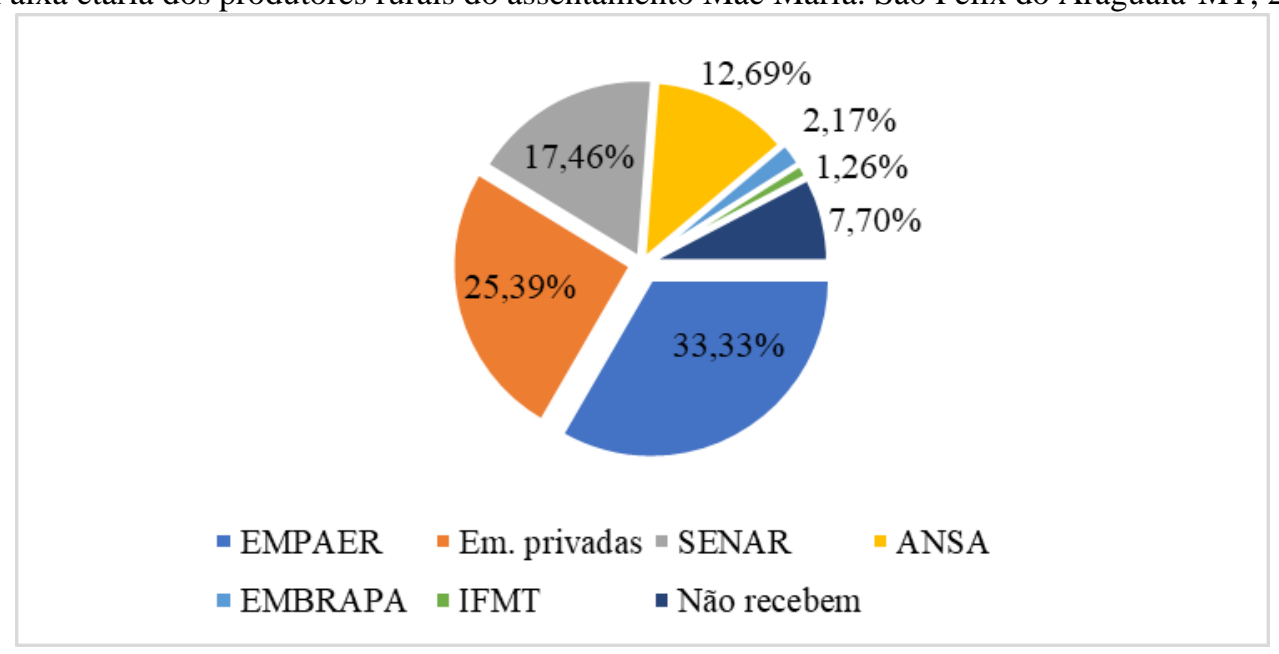

Fonte: Barbosa, 2019.

O número de indivíduos em um grupo familiar no assentamento variou entre: uma pessoa $(8,27 \%)$, dois indivíduos $(51,03 \%)$, três $(21,23 \%)$ e, por quatro pessoas ou mais $(19,31 \%)$. Vale ressaltar que o predomínio de famílias constituídas por duas pessoas, esses são aqueles casais de mais idade cujos filhos saíram da unidade familiar em busca de qualificação profissional nos centros urbanos ou para constituírem suas próprias famílias.

Essas informações revelam um cenário preocupante em relação à permanência dos jovens no meio rural. Segundo Moura e Silva (2012), a pretensão dos jovens de não continuar vivendo no campo é justificada pelas dificuldades enfrentadas para se manter economicamente 
na agricultura com baixos preços nos produtos agrícolas, trabalho árduo e terras insuficientes além de outros atrativos que chamam atenção no meio urbano.

De acordo com Waldemar e Wesz (2009), um dos principais problemas é em relação ao tamanho das propriedades, o que acaba originando unidades com pequenos espaços de área insustentáveis para a manutenção da família. Ainda conforme os autores, esse problema acaba forçando a saída de grande parte dos integrantes da unidade doméstica para fora do meio rural e deixando os domicílios sem futuros sucessores.

O êxodo dos jovens do meio rural é revelador da situação e percepção dos jovens sobre a realidade em que vivem e indicador de que estamos vivendo um acelerado período de transformação no qual a incerteza parece predominar (PUNTEL; PAIVA; RAMOS, 2011). Deste modo, produz um cenário em que a maioria da população que permanece nas propriedades estão acima dos 50 anos, um exemplo, visto no projeto de assentamento.

No que diz respeito ao tempo de permanência na propriedade, cerca de $17,42 \%$ dos entrevistados vivem de 0 a 05 anos, 24,24\% de 05 a 10 anos, entorno de $18,18 \%$ residem de 10 a 15 anos, enquanto 40,15\% entre 15 a 20 anos, deste último percentual 39,31\% estabeleceram domicílio desde o ano de ocupação (que se deu em 1999).

A maior parte das famílias residentes após a data de ocupação, permitiu inferir que estes adquiriram a propriedade por meio de contrato de compra e venda, com o objetivo em sua grande maioria para a formação de pastagens para criação de gado de corte ou melhoria de vida.

A mão de obra predominantemente utilizada na realização das tarefas é a familiar com $80,68 \%$, seguida de $12,41 \%$ de trabalhador temporário e $6,89 \%$ de mão de obra fixa. Resultados semelhantes foram obtidos por Silva et al. (2017), pesquisando o mesmo projeto de assentamento, onde afirmaram que cerca de $80,95 \%$ da mão de obra é oriunda do grupo familiar.

$\mathrm{O}$ percentual de indivíduos representados em ambas as pesquisas, afirmam que o assentamento está em conformidade com as diretrizes da lei Federal n. 11.326, de 24 de julho de 2006, no artigo $3 .^{\circ}$, onde designa agricultura familiar como sendo aquela que utilize predominantemente mão-de-obra da própria família nas atividades econômicas do seu estabelecimento ou empreendimento (BRASIL, 2006).

Quanto a renda média familiar em Salários Mínimos (SM) dos entrevistados, cerca de 43,44\% das famílias ganham até um SM, 48,96\% de dois a três SM e 7,58\% relataram receber dentre três a cinco SM. Confort et. (2016) alcançaram resultados similares no Município de Muniz Freire - ES, nos quais 43,91\% dos agricultores entrevistados relataram obterem renda menor ou igual a um salário mínimo. 
A renda média abaixo do esperado, obtida por estes agricultores é reveladora dos desafios que eles enfrentam para trabalhar no campo, afetando diretamente em sua permanência, acabando por acelerar ainda mais a especulação imobiliária, o arrendamento da terra e o êxodo rural na agricultura familiar.

Os agricultores familiares que recebem até um salário mínimo são maioria. Diversificar a produção nas propriedades pode gerar um impacto social significativo no aumento da renda, em um cenário em que a pecuária bovina está presente em $46,89 \%$ das propriedades, com destaque para o gado leiteiro, corroborando com a pesquisa desenvolvida por Barbosa e Ramos (2019) no mesmo PA, constatando uma expressividade de 54,41\%.

De acordo com Silva et al. (2019) a monocultura, como em toda atividade econômica traz uma simplificação das operações financeiras, de produção e de comercialização. Mas, limita os produtores a pensarem na propriedade na totalidade, ficando cedidos somente a uma cultura ligada a um sistema integrado de produção.

Acredita-se que, por meio da pluriatividade, os agricultores familiares possam estabelecer iniciativas de diversificação das suas ocupações interna e externamente à unidade de produção, bem como aumentar as fontes e as formas de acesso às rendas (SCHNEIDER, 2007).

Cabe salientar que as atividades secundárias desenvolvidas no PA são destinadas quase que exclusivamente para o consumo familiar, como a criação de aves e suínos, cultivo de hortaliças e pomares, produção de ovos e mandioca, e seus derivados, sendo vendido uma escala mínima para alguns atravessadores na própria propriedade ou feiras livres em municípios vizinhos.

Diante dessa realidade, uma parcela significativa dessas famílias $(35,17 \%)$ afirmaram terem atividades "não agrícola" como principal fonte de renda (aluguéis, empreendimentos comerciais e entre outros) ou se veem obrigados a realizar tarefas fora de suas propriedades, seja na realização de atividades no próprio meio rural, mediante o trabalho braçal como na confecção e reparos de cercas, ou no meio urbano, exercendo atividades por meio de contratos, carteira assinada, serviços públicos e entre outros.

Diante disso, Lazaroto e Raiher (2013, p.20) destacam que "o meio rural da forma em que está configurado não é capaz de gerar recursos financeiros suficientes para a manutenção dos domicílios agrícolas, onde os agentes buscam fora da propriedade tais recursos, tornando essas atividades não rurais, em muitos casos, as principais atividades". 
É importante salientar que 17,24\%, declararam receber algum tipo de benefício social do governo como principal fonte de renda, com maior expressividade para aposentadoria. Portanto, convém distinguir com clareza que as rendas obtidas via aposentadorias, pensões e outras formas de transferências públicas de recursos financeiros não fazem parte da composição da renda do tipo "não agrícola" (SILVA; SIMIONI; TALAMINI, 2009).

Outros entraves que interferem na diversificação dos meios de produção perceptíveis na região são: as vias de acesso sem pavimentação asfáltica, deficit hídrico em determinada época do ano, necessidade de criação de programas de associativismo e cooperativismo, resistência de agricultores em adotar medidas de inovação tecnológica, falta de conhecimento técnico, dentre outros.

\subsection{Assistência Técnica e Extensão Rural na percepção dos assentados}

No Brasil, a agricultura familiar é a principal responsável pela produção de alimentos para o consumo interno. Contudo, "é notável a falta de assistência técnica e baixa adoção de inovações tecnológicas, tornando necessário a adoção de políticas que possam auxiliar os agricultores a alavancarem seus sistemas produtivos" (GOMES; GUIMARÃES; PORRO, 2017).

"A ATER é considerada uma forma de educação não formal, de caráter continuado existente no meio rural para promover o processo de gestão da produção, assim como o beneficiamento e comercialização agropecuárias" (BRASIL, 2010).

Neste sentido, Nascimento e Nascimento (2020) abordam que:

É necessário ouvir aqueles que estão recebendo o serviço de ATER contatado pelo projeto público. O que permite identificar informações sobre as expectativas, percepção de desempenho e críticas dos agricultores avaliados. Dados valiosos para aprimorar a qualidade e gestão dos serviços (NASCIMENTO; NASCIMENTO, 2020, p. 74).

Diante dessa situação, no PA Mãe Maria, cerca de 63,63\% dos entrevistados declaram já terem ouvido falar dos serviços da ATER. Deste percentual, aproximadamente 21,42\% não sabe qual a definição desta política e cerca de 42,21\% definem em cinco significados: 56,06\% definiram ATER como o acompanhamento de um profissional nas atividades realizadas dentro da propriedade, $28,78 \%$ como suporte dado ao agricultor, 7,57\% relataram ser um profissional responsável pela liberação da Declaração Aptidão ao Programa Nacional da Agricultura 
Familiar (DAP), 6,06\% entendem que seja uma orientação recebida de um técnico nas atividades realizadas pelo produtor e $1,51 \%$ como benefício doado pela prefeitura.

Mediante essas informações, pode-se observar que a grande maioria dos agricultores faz uma associação do significado com a palavra assistência, que de acordo com o Dicio (2020) tem como definição: a ação de ajudar, de dar auxílio, de assistir, de estar presente. Enquanto a palavra técnica ainda em conformidade com o Dicio e definido como: perito, profissional e especialista, ou seja, um indivíduo que tem conhecimento prático, visto pelos agricultores como um técnico profissional na área de agricultura ou pecuária, responsável por prestar auxílios nas atividades e liberação da DAP.

Referente ao conceito de extensão rural, palavra com significado menos assimilativo, o percentual de entrevistados que não souberam sua definição se destaca com $83,33 \%$ dos entrevistados, enquanto 16,66\% deram uma definição, destes, $31,81 \%$ chegaram mais próximo possível do conceito de extensão rural, relatando como sendo "o ato de levar a informações técnicas ao agricultor”. Diante desse fato, é relevante destacar o baixo nível de escolaridade e pouco conhecimento das políticas voltadas para estes agricultores. Contudo, a análise desse parâmetro permiti entender que o contato do assistente técnico e extensionista no PA se dá de forma superficial e sem nenhuma preocupação com a missão da extensão rural na vida do agricultor.

Dos entrevistados, 37,12\% afirmaram que receberam algum tipo de Assistência na propriedade pelo menos uma vez. Resultados semelhantes foram encontrados por Gomes; Guimarães e Porro (2017) pesquisando no nordeste paraense, constataram que 70,8\% dos agricultores não receberam nenhum tipo de assistência técnica. Enquanto Freitas et al., (2013) encontraram situações diferentes no Município de Juína-MT, no qual 63\% dos entrevistados afirmaram receber ou já terem recebido serviços de ATER.

De acordo com os princípios da ATER, seu acesso deve ser gratuito, em qualidade e quantidade suficiente, visando o fortalecimento da agricultura familiar (BRASIL, 2010). No entanto, os serviços de ATER atualmente desenvolvidos, ainda são insuficientes, não atendendo a demanda efetiva dos produtores familiares no assentamento. A carência de unidades locais e o baixo número de técnicos explicam essa circunstância.

Segundo os autores Carmo e Galognese (2010), a capacitação e qualificação profissional são fundamentais para quem busca um aprimoramento da sua atividade. Sendo assim, com relação a capacitação dos agricultores, essa ocorre principalmente por meio de cursos ofertados pela EMPAER (33,33\%), empresas privadas (25,39\%), seguido de $17,46 \%$ de cursos prestados 
por Serviço Nacional de Aprendizagem Rural (SENAR), entorno de 12,69\% oferecidos pela Associação de Educação e Assistência Nossa Senhora da Assunção (ANSA), aproximadamente 2,17\% através da Empresa Brasileira de Pesquisa e Agropecuária (EMBRAPA) e com menos expressividade o Instituto Federal de Mato Grosso - IFMT Campus Confresa (1,26\%), lembrando que $7,7 \%$ afirmam nunca ter recebido. Conforme pode se observar na figura 02.

Figura 02 - Órgãos, empresas e instituições que ofereceram algum tipo de ATER no assentamento Mãe Maria. São Félix do Araguaia - MT, 2019.

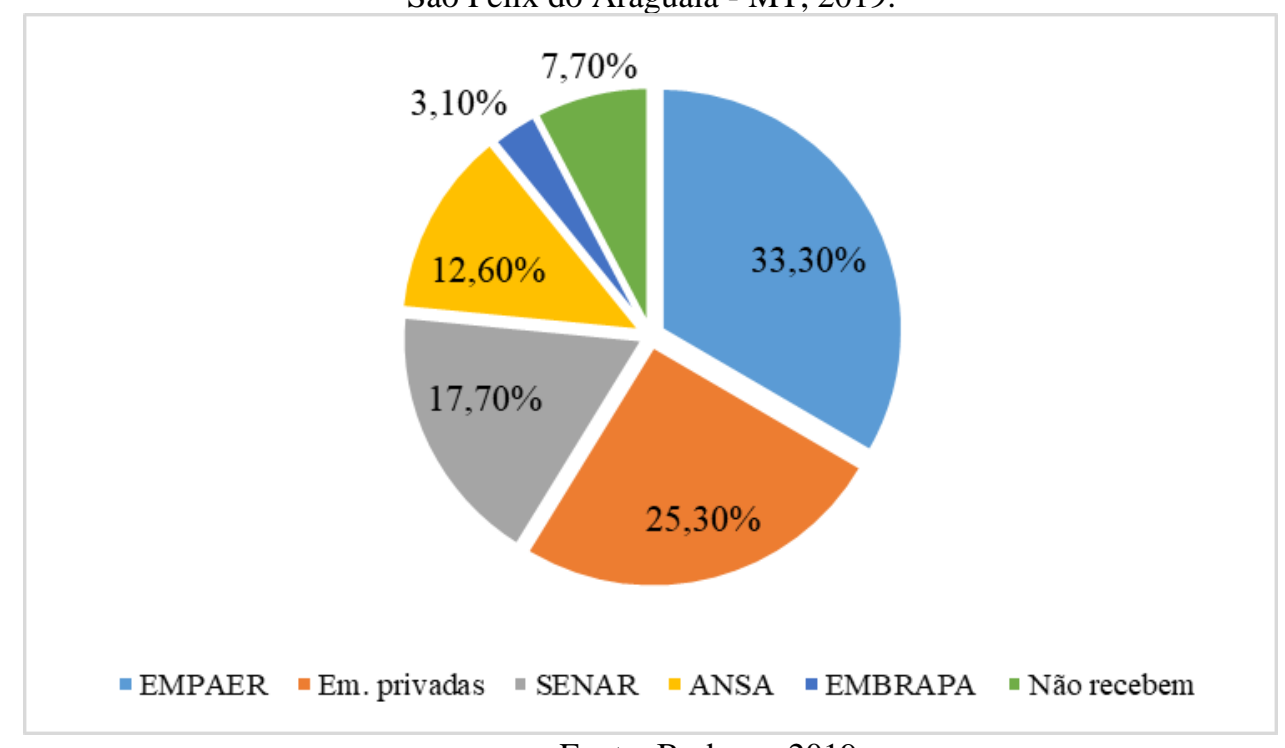

Fonte: Barbosa, 2019.

Em relação as orientações prestadas por estas instituições, é possível observar que o Serviço Nacional de Aprendizagem Rural (SENAR) e Associação de Educação e Assistência Nossa Senhora da Assunção (ANSA) se destacam por oferecerem diferentes tipos de treinamentos a esses agricultores, dentre elas, a doma racional, defumação de produtos cárneos, reflorestamento de áreas degradadas, manejo de gado leiteiro, inseminação artificial, controle de cupim, vacinação contra as principais doenças nos bovinos, manejo de pastagens, apicultura, entre outros. Em adição, a EMPAER exerce garantias e segurança jurídica durante no processo de liberação de créditos aos produtores.

A interação da ANSA no assentamento está comumente ligado à sua fundação, sediada no município de São Félix do Araguaia, é uma instituição sem fins lucrativos atua no meio rural com atividades de recuperação de áreas por meio do reflorestamento com mudas de plantas nativas. Enquanto o SENAR é uma instituição de direito privado que atende um número maior de agricultores no Estado, se destacando em alguns assentamentos da região, como observado por Barbosa (2017) no PA Independente I no município de Confresa, com um percentual relevante de $31,25 \%$. 
De maneira geral, observa-se que $71,42 \%$ dos produtores rurais chegaram a aplicar os conhecimentos adquiridos na propriedade, obtendo resultados satisfatórios em 91,42\% das atividades desenvolvidas. Cabendo ressaltar que estes fazem o uso contínuo das orientações em que auxiliam em suas atividades de maior interesse econômico como o aporte produtivo do gado de leite e corte, onde as demais capacitações prestadas (apicultura, defumação de produtos cárneos, reflorestamento de áreas degradadas, doma racional etc.,) não despertaram o interesse dos agricultores familiares, tendo como justificativa de falta de matéria prima, mercado e até mesmo o próprio desinteresse do produtor.

Quando perguntado sobre o que é política pública, 83,00\% dos pesquisados não souberam ou não quiseram responder. É interessante ressaltar que essa negativa é uma forma de repúdio a palavra "política", que no entender dos agricultores se referem à política partidária, demonstrando assim total insatisfação com o cenário político atual. No entanto, 17\% responderam que são bens e serviços prestados pelo governo, como meio de auxiliar os agricultores no manejo da propriedade.

Outro fato relevante que deve ser levado em consideração, é no que diz respeito às políticas públicas para os agricultores no assentamento, pois, a pesar da importância para o país, os autores Castro e Pereira (2017) afirmam que os agricultores familiares sempre receberam pouco suporte do poder público, sendo comparativamente negligenciado pelas diversas esferas governamentais ao longo da modernização agrícola brasileira.

A desvalorização do meio rural frente as inúmeras dificuldades vivenciadas no âmbito da agricultura familiar ao longo dos anos trouxeram consigo um conceito culposo do olhar governamental a essa classe. No entanto, não se descarta o nível de escolaridade, o que dificulta o entendimento do agricultor sobre a distinção do tema abordado.

Tendo em vista a importância da ATER para o desenvolvimento regional, e os prejuízos que sua ausência causa para a sociedade, $26,51 \%$ afirmaram que sua ineficácia está relacionada a pouca atuação dos órgãos públicos no assentamento, notando certa carência de profissionais para realizar visitas com mais frequência. Cerca de 49,24\% defendem que falta apoio do governo das esferas, municipal, estadual e federal é o que dificulta as atividades de ATER, logo 11,36\% apontaram desinteresse por parte do próprio agricultor em procurar o serviço público em prol da tecnificação dos meios de produção.

Quando questionados sobre o que seria uma ATER de qualidade, 24,24\% não souberam responder, e $32,6 \%$ defenderam que seria aquela no qual as visitas pudessem ser realizadas com frequência, com disponibilidade de recursos tecnológicos para auxiliarem nas atividades. Os 
demais abordam assuntos relacionados a liberação de créditos e execução de projetos liberados com acompanhamento do profissional da ATER desde a implantação ao meio de comercialização dos produtos obtidos. É importante destacar que somente 36,84\% afirmaram ter procurado ao menos uma vez, seja para sanar dúvidas ou realização de procedimentos técnicos dentro da propriedade, enquanto os demais, não houve nenhum tipo de procura.

\subsection{Dificuldades encontradas pelos agricultores no PA Mãe Maria no município de São}

\section{Félix do Araguaia-MT}

Haja vista que grande parte dos alimentos colocados a mesa do consumidor brasileiro é advinda da agricultura familiar. No entanto, os produtores no estado sofrem para alcançar uma escala mínima de produção, principalmente devido às limitações na capacidade de investimento, falta de assistência técnica e acesso às novas tecnologias de modo a ampliar sua produtividade (Castro; Pereira, 2017).

As principais dificuldades encontradas no PA Mãe Maria, foram financeiras $(68,93 \%)$, seguida da falta de informação (34,09\%), e 30,30\% se dividem em dificuldades tecnológicas e limitações físicas. Resultados diferentes foram encontrados pelos autores Gomes; Guimaraes e Porro (2017), onde 66\% dos problemas enfrentados pelos agricultores familiares entrevistados no Nordeste Paraense foram a falta de mecanização.

Contudo, as dificuldades financeiras afirmadas pelos produtores rurais do PA, advêm da presunção que a solução de todo os problemas seja a existência monetária, no qual está supre todas as dificuldades existentes no meio rural com a compra de suplementos e maquinários agrícolas e até mesmo a existência de um profissional com mão de obra particular na propriedade.

As limitações físicas no PA existem em grande parte das propriedades, ao qual é possível observar a existência de moradores idosos, sendo estes mais suscetíveis a doenças e desgastes, e encontrando limitações no desenvolvimento das atividades, torna-se necessário o uso de mão de obra terceirizada continua, principalmente na ordenha do gado leiteiro.

De acordo com Lourenzani (2014) existe uma série de fatores que afetam significativamente o desempenho dos empreendimentos rurais, entre elas o autor destaca que: 
familiares. Tal deficiência provoca impactos negativos no desenvolvimento desse segmento e, consequentemente, na sua integração aos mercados mais dinâmicos (LOURENZANI, 2014, p. 314).

Uma vez implantado nos assentamentos os agricultores são beneficiados com créditos de fomento, habitação, custeio e investimento. No que se refere aos auxílios prestados pelo governo no PA, 71,96\% afirmam já ser beneficiário de um ou mais programas, tais como: o custeio representando, 50,90\%, seguido do Programa Nacional de Fortalecimento da Agricultura Familiar (PRONAF) com 48,48\% e auxílio na habitação rural 18,78\%.

Diante dessa realidade, nota-se, que a grande parte desses agricultores no assentamento possuem pouco ou nenhum treinamento para gerir o recurso financeiro, empregando nos meios de produção com adoção de inovação tecnológica, uma vez que a maioria $(41,26 \%)$ utilizam a técnica de tentativa e erro, outros $32,03 \%$ por meio de experiências adquiridas pela troca de conhecimento, entorno de $16,99 \%$ através de treinamentos, seguido de $7,76 \%$ que procuram informações em casas agropecuárias no momento da compra de produtos agropecuários e $1,94 \%$ através de técnicos das empresas públicas ou privadas, conforme representado na figura 03.

Figura 03 - Formas de aquisição dos conhecimentos aplicados no desenvolvimento das atividades agropecuárias pelos produtores rurais do PA Mãe Maria. São Félix do Araguaia - MT, 2019.

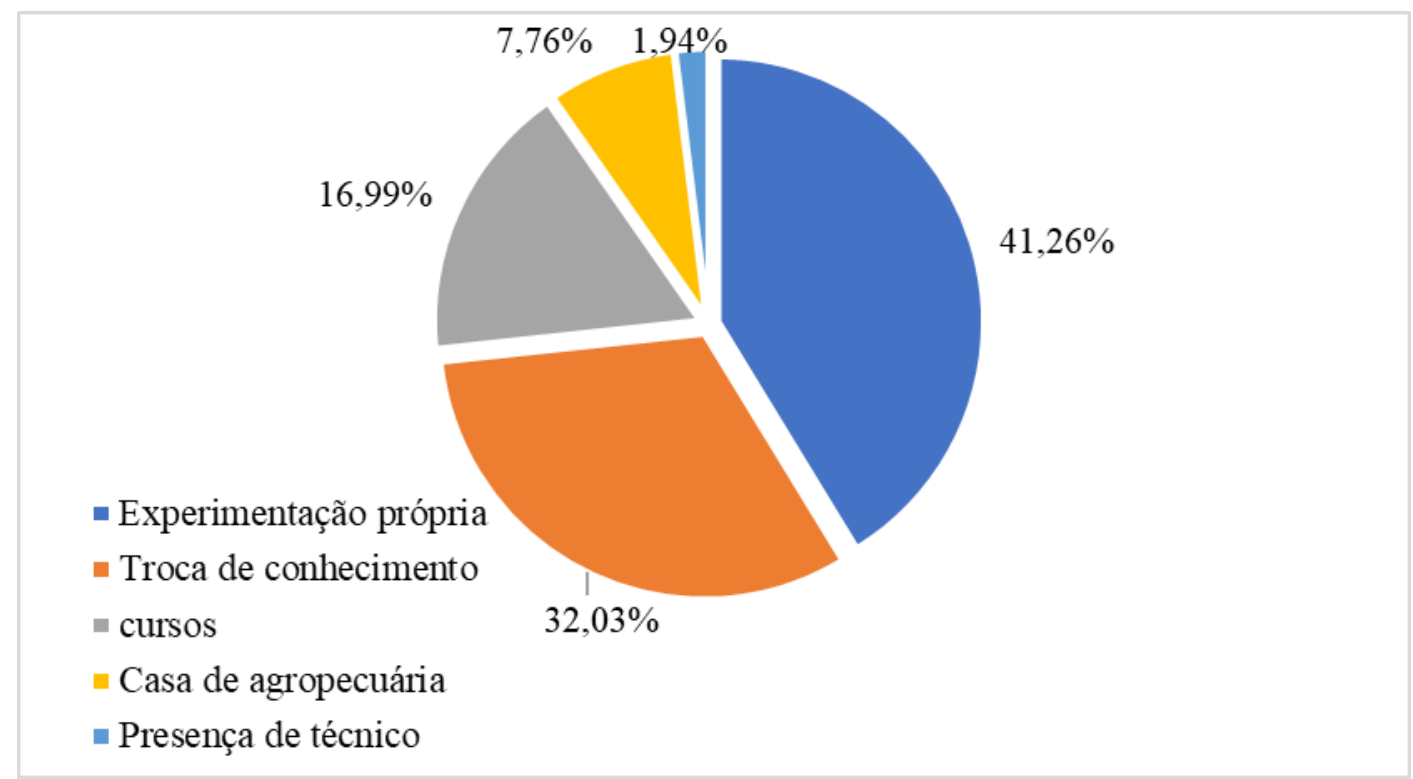

Fonte: Barbosa, 2019.

O nível de capacitação destes agricultores é consideravelmente incisivo nas tomadas de decisões em suas produtividades, valendo salientar que (ALVES, 2006. p. 11) "sem ajuda externa, o agricultor não consegue vencer as barreiras que se antepõem à adoção de tecnologia 
e ao planejamento do negócio. Por si mesmo, o agricultor não se livrará da rotina, e nem mesmo saberá imitar os mais bem-sucedidos".

Apesar da existência de créditos no assentamento, é notável que as dificuldades são inúmeras. Uma das principais limitações no PA é a necessidade de diversificação de produção, que segundo Barbosa et al. (2016) "pode ser uma alternativa para agricultores familiares aumentarem seus rendimentos e por consequência, melhorar a qualidade de vida no campo". No entanto, Arruda e Araújo (2019) ressaltam que "os agricultores encontram dificuldades para acessar crédito para investir em sistemas de produção diversificados. O principal obstáculo está na capacidade das agências bancárias para avaliar a rentabilidade desses sistemas de produção".

De acordo com Castro e Pereira (2017) "não basta conceder crédito para o agricultor familiar se ele não tiver as informações adequadas para melhorar sua produção agrícola". Permitindo analisar que, os recursos financeiros emprestados sem as devidas orientações técnicas, proporciona um retorno financeiro insatisfatório para o agricultor familiar, dificultando sua sobrevivência no campo.

Conforme Castro e Pereira (2017):

\begin{abstract}
A baixa capacidade dos órgãos estaduais de auxiliarem e elaborarem, em parceria com os agricultores, projetos mais completos e adaptados às condições locais, essas instituições, com frequência, elaboram projetos simplificados e com pouca análise, servindo como mero instrumento para liberação do crédito do Pronaf (CASTRO; PEREIRA, 2017, p. 20).
\end{abstract}

Como resultado dessas afirmações, além da pouca diversificação de produção, observase no PA a necessidade de planejamento das atividades, principalmente na criação de gado, que é a principal fonte de renda dos agricultores. Nesse contexto, a formação e manutenção das pastagens se torna essencial, no entanto o agricultor realiza somente a gradagem da área a ser cultivada e em seguida procede com a semeadura da forrageira a lanço no início do período chuvoso, favorecendo o desenvolvimento de plantas daninhas, provocando queda na produtividade.

A alimentação dos bovinos no assentamento é basicamente feita com pastagem associada ao suplemento mineral, em sistema extensivo na maioria das propriedades. É possível observar que somente duas propriedades adotam a prática de manejo nutricional alternativo para os animais na época da seca (período de abril a setembro), sendo elas da mesma família, onde realizam o cultivo de cana-de-açúcar para o preparo do composto com demais aditivos no qual é inserido na alimentação do gado leiteiro. 
É importante destacar que quando perguntados se alguma vez chegaram a procurar algum órgão para orientação na realização de alguma atividade praticada na propriedade, 36,84\% afirmaram ter procurado ao menos uma vez, seja na liberação do DAP ou para sanar dúvidas, enquanto os demais, não houve nenhum tipo de procura.

Na maioria das ocasiões, o auxílio prestado ao produtor é de profissional, um agrônomo, técnico agrícola ou o veterinário contratado por empresas de produtos agropecuários. Esses são indivíduos essenciais na vida desses agricultores, porém vale lembrar que esses profissionais trabalham com a necessidade de cumprir metas dentro da empresa, o que muitas vezes interfere na qualidade da assistência técnica prestada.

Contudo, pode-se observar o desejo desses agricultores em permanecerem no meio rural, pois mesmo em meio a tantos desafios, os mesmos persistem em permanecer no campo, haja vista que a maioria $(84,82 \%)$ declaram não ter intenção de vender a propriedade, pois acreditam em uma vida mais árdua fora meio rural e 16,18\% relataram ter interesse em vender seu terreno, sendo que destes, $54,55 \%$ mudariam para o meio urbano explicado pela inviabilização econômica e busca de melhores condições de vidas, e 45,45\% adquiririam propriedades em outras regiões. O percentual de indivíduos que almejam adquirir outra terra, mostra a insatisfação com a localização de sua unidade ou até mesmo com a região.

\section{Considerações}

De maneira geral, o estudo possibilitou fazer uma análise do cotidiano dos agricultores familiares no que se refere aos serviços da ATER no PA Mãe Maria do município de São Félix do Araguaia - MT. O que possibilitou observar que as políticas voltadas nesse PA ainda têm muito a ser aprimorada.

É possível observar que pecuária bovina é a principal atividade exercida pelos assentados, com um percentual de $46,89 \%$ e as demais fontes de rendas são exercidas por meio de trabalhos "não agrícolas".

Os cursos de capacitação realizados, tem níveis de eficácia consideráveis, no entanto há pouca atuação dos agentes responsáveis por prestar esses serviços no assentamento de maneira contínua, principalmente por instituições públicas. O que dificulta os agricultores explorarem a diversidade em suas propriedades.

De certo modo, o pouco entendimento dos agricultores familiares a respeito da ATER está principalmente associado ao baixo nível de escolaridade e ao pouco conhecimento dos 
recursos disponíveis para o aprimoramento de suas atividades, além da carência desses serviços no assentamento. Ademais, o principal desafio dos agricultores é o financeiro.

Deste modo, fica evidente que esses agricultores necessitam de políticas governamentais que fomentam suas atividades e atuem não só em números, mas também na melhoria da capacitação de profissionais que trabalham de modo permanente, com o objetivo de incentivar a diversidade de produção e o uso de inovações tecnológicas. Permitindo assim, inserir o agricultor no mercado de negócios, estimulando a economia, a permanecia dos mais jovens no campo e consequentemente reduzir de maneira significativa o êxodo rural.

\section{Referências}

ALVES, E. Migração rural-urbana, agricultura familiar e novas tecnologias. Embrapa Informação Tecnológica, Brasília, DF, p. 181, 2006. Disponível em: https://ainfo.cnptia.embrapa.br/digital/bitstream/item/158944/1/migracao-rural-urbana.pdf. Acesso em: 21 ago. 2020.

ANDRADE, L. B. P. Percurso metodológico. Cultura Acadêmica, São Paulo, p. 38, 2010. Disponível em: http://books.scielo.org/id/h8pyf/pdf/andrade-9788579830853-05.pdf . Acesso em: 29 ago. 2020 .

ARRUDA, R. V. de; ARAÚJO, V. P. D. A agricultura familiar e as causas que geram o Êxodo Rural. Enciclopédia biosfera, Goiânia, v.16 n.29; p. 1-16. 2019. Disponível em: http://www.conhecer.org.br/enciclop/2019a/agrar/a\%20agricultura\%20familiar.pdf. Acesso em: 15 de out. 2020.

Assistência. In: DICIO, Dicionário Online de Português. Porto: 7 Graus, 2020. Disponível em: https://www.dicio.com.br/trabalho/. Acesso em: 30 ago. 2020.

ALBUQUERQUE, E. S. Politicas Sociais Públicas e a Juventude Rural. In: Congresso Nacional do CONPEDI, 23, 2014, João Pessoa. Anais... João Pessoa, PB: Universidade Federal da Paraíba, 2014, p. 264-293.

BARBOSA, A. A. Agricultura familiar: Levantamento dos Sistemas de Produção Pecuária no Projeto de Assentamento Independente I no município de Confresa - MT. 2017. 64. Trabalho de conclusão de curso (Bacharelado em Agronomia) - Instituto Federal de Educação, Ciência e Tecnologia - Campus Confresa Mato Grosso, Confresa, 2017.

BARBOSA, J. A; RAMOS, P. R. Conhecendo a Realidade Produtiva de Leite dos Agricultores Familiar do Projeto de Assentamento Mãe Maria no Município de São Felix do Araguaia-MT. In: Jornada de Ensino Pesquisa e Extensão: Ensino, Pesquisa e Extensão. Na Formação Integral Dos Sujeitos Na Região Do Araguaia Xingu, 3, 2019, Confresa. Anais... Confresa, MT: Instituto Federal de Educação Ciência e Tecnologia De Mato Grosso - Campus Confresa, 2019. p. 3-7.

BARBOSA, P. J. F. A importância da diversificação agrícola como complemento na renda familiar na região de Manhuaçu-MG. Centro de Ciência Economia e Matemática - CCEI, Bagé, RS, v. 20, n. 35, p. 11, 2016. Disponível em:

http://revista.urcamp.tche.br/index.php/Revista_CCEI/article/view/57 . Acesso em: 04 de abr. 2020. 
BIAQUINI, E. S. et al. A complementaridade dos métodos qualitativos e quantitativos de pesquisa: estudo de caso da Igreja Particular de Londrina. In: Congresso Brasileiro de Ciências da Comunicação, 33., 2010, Caxias do Sul. Sociedade Brasileira de Estudos Interdisciplinares da Comunicação... Caxias do Sul, RS: INTERCOM, 2010. p. 2-15. Disponível em: http://www.intercom.org.br/papers/nacionais/2010/resumos/R5-2692-1.pdf. Acesso em: 29 ago. 2020.

BRASIL. Lei ${ }^{\circ}$ 11.326, de 24 de julho de 2006. Estabelece as diretrizes para a formulação da Política Nacional da Agricultura Familiar e Empreendimentos Familiares Rurais. Senado Federal, Brasília, DF, v.1, n.1, p. 1-2. Disponível em: http://www.planalto.gov.br/ccivil_03/_ato20042006/2006/lei/111326.htm . Acesso em: 04 de abr. 2020.

BRASIL. Lei no 12.188, de 11 de janeiro de 2010. Altera a Lei no 8.666, de 21 de junho de 1993 e dá outras providências, que a Política Nacional de Assistência Técnica e Extensão Rural para a Agricultura Familiar e Reforma Agrária - PNATER e o Programa Nacional de Assistência Técnica e Extensão Rural na Agricultura Familiar e na Reforma Agrária - PRONATER. Diário Oficial da República Federativa do Brasil, Brasília, DF, p. 1-5, 11 jan. 2010. Disponível em: http://www.planalto.gov.br/ccivil_03/_ato2007-2010/2010/lei/112188.htm. Acesso em: 13 de mai./2020.

CARMO, R. M.; COLOGNESE, S. A. Qualificação e permanência do agricultor familiar no campo: a casa familiar rural do município de Candói -PR. Revista Trivium, Pitanga, PR, v. 1, n. 1, p. 17, out/dez., 2010. Disponível em:

https://educanp.weebly.com/uploads/1/3/9/9/13997768/qualificao_e_permanncia_do_agricultor_famili ar_no_campo_a_casa_familiar_rural_do_municpio_de_candi_-_pr.pdf. Acesso em: 04 de abr. 2020.

CASTRO, C. N.; PEREIRA, C. N. Agricultura familiar, assistência técnica e extensão rural e a política nacional de ATER. Texto para Discussão (IPEA), Brasília, v. 2343, p. 1-48, 2017.

Disponível em: http://repositorio.ipea.gov.br/bitstream/11058/8114/1/td_2343.PDF. Acesso em: 13 out. 2020.

CONFORT, A. M. Á. dá S. et al. Perfil Socioeconômico de Agricultores Familiares do Município de Muniz Freire. Revista Guará, Espírito Santo, v. 5, n.5, p. 4-6, 2016. Disponível em https://periodicos.ufes.br/index.php/guara/article/view/14351. Acesso em: 04 de abr. 2020.

FERRO, A., de S.; VECHI J., B. Contextualização da Agricultura Familiar em Mato Grosso. In: OFICINA DE CONCERTAÇÃO ESTADUAL DE MATO GROSSO, 2., 2014, Sinop. Integração Ensino, Pesquisa, ATER, Agricultura Familiar... Sinop, MT: EBRAPA agrossilvipastoril, 2014. p. 8-31. Disponível em:

https://www.embrapa.br/documents/1354377/2109296/Documento+base+contextualiza\%C3\%87\%C3 \%830.pdf/247bf759-27f9-4b4e-afad-1aa6cabd18d4?version=1.0. Acesso em: 03 de abr. 2020.

FREITAS, E. S. et al. Assistência técnica e extensão rural: a percepção do produtor rural do município de Juína. In: JORNADA CIENTIFICA DO IFMT - CAMPUS JUÍNA, 2., 2013, Juína.

Desenvolvimento e produção: a caminho da sustentabilidade... Juína: Instituto Federal de Mato Grosso - Campus Juína, 2013. p. 5-8. Disponível em:

https://www.bibliotecaagptea.org.br/administracao/extensao/artigos/ASSISTENCIA\%20TECNICA\%

20E\% 20EXTENSAO\%20RURAL\%20A\%20PERCEPCAO\%20DO\%20PRODUTOR\%20RURAL\%2 0DO\%20MUNICIPIO\%20DE\%20JUINA.pdf . Acesso em: 04 de abr. 2020.

GOMES; D.; GUIMARÃES, J.; PORRO, R. Acesso à ATER e os principais problemas técnicos enfrentados pela agricultura familiar no nordeste paraense. In: Congresso Internacional das Ciências Agrárias, 2, 2017, Recife. Anais...Recife: Instituto IDV, 2017. Disponível em: https://cointerpdvagro.com.br/wp-content/uploads/2018/02/ACESSO-\%C3\%80-ATER-E-OS-PRINCIPAIS- 
PROBLEMAS-T\%C3\%89CNICOS-ENFRETADOS-PELA-AGRICULTURA-FAMILIAR-NONORDESTE-PARAENSE.pdf. Acesso em: 03 ago. 2021.

IBGE. Instituto Brasileiro de Geografia e Estatística. Cidades e estados. Brasília. 2017. Disponível em: https://www.ibge.gov.br/cidades-e-estados/mt/sao-felix-do-araguaia.html. Acesso em: 03 de abr. 2020 .

INSTITUTO NACIONAL DE COLONIZAÇÃO DE REFORMA AGRÁRIA (INCRA). Relatório dos Assentamentos rurais de Mato Grosso. Informativo técnico: 2017.

LAFORGA, G.; VIEIRA, A. O. Ação extensionista da EMPAER frente à nova PNATER: uma análise a partir do Assentamento Guapirama, Campo Novo do Parecis - MT. In: CONGRESSO DA SOCIEDADE BRASILEIRA DE ECONOMIA, ADMINISTRAÇÃO E SOCIOLOGIA RURAL, 46., 2008, Rio Branco. XLVI Congresso da SOBER em Rio Branco... Rio Branco, AC: SOBER, 2008. p. 2-19. Disponível em:

https://www.researchgate.net/publication/242411823_acao_extensionista_da_empaer_frente_a_nova_ pnater_uma_analise_a_partir_do_assentamento_guapirama_campo_novo_do_parecis_-_mt. Acesso em: 03 de ag. 2020.

LAZAROTO, J. T.; RAIHER, A.P. Determinantes da renda e pobreza dos agricultores do Vale do Ribeira. Política Agrícola, v. 1, p. 5-25, 2013. Disponível em:

https://ainfo.cnptia.embrapa.br/digital/bitstream/item/86544/1/Determinantes-da-renda-e-pobreza-dosagricultores-do-Vale-do-Ribeira.pdf. Acesso em: 21 ago. 2020.

LOURENZANI, W. L. Capacitação gerencial de agricultores familiares: uma proposta metodológica de extensão rural. Organizações Rurais e Agroindustriais (UFLA), Lavras, v. 8, n. 3, p. 314-322, 2006. Disponível em: https://core.ac.uk/download/pdf/7052669.pdf. Acesso em: 04 de abr. 2020.

MOURA, A. M. P. de; SILVA, G. M. G. Agricultura Familiar: Perspectiva de permanência dos jovens no campo do município de Igaci/Alagoas. In: ENCONTRO NACIONAL DE GEOGRAFIA AGRÁRIA, 21, 2012, Uberlândia. Resumos... Uberlândia: Universidade Federal de Uberlândia, 2012. p. 1-20. Disponível em: http://www.lagea.ig.ufu.br/xx1enga/anais_enga_2012/eixos/1092_1.pdf . Acesso em 21 de out. 2019.

NASCIMENTO, A. S. P.; NASCIMENTO, J. S. P. Assistência Técnica e Extensão Rural: A Percepção de Satisfação do Serviço Prestado às Associações Atendidas por um Projeto Público de Desenvolvimento Rural no Território do Médio Sertão Paraibano. Revista Geotemas, Pau dos Ferros, RN, v. 10, n. 1, p. 29, 2020. Disponível em:

http://periodicos.uern.br/index.php/geotemas/article/view/4229 . Acesso em: 03 de out. 2019.

PUNTEL, J. A.; PAIVA, C. A. N.; RAMOS, M. P. Situação e perspectivas dos jovens rurais no campo. In: CONFERÊNCIA DE DESENVOLVIMENTO CODE/IPEA, 2., 2011, Brasília. Anais da II Conferência de Desenvolvimento CODE/IPEA... Brasília: CODE/IPEA, 2011. v. 1. p. 35-50. Disponível em: https://www.ipea.gov.br/code2011/chamada2011/pdf/area3/area3-artigo20.pdf. Acesso em: 21 ago. 2020.

QUEIROZ, L. I. da S.; COSTA, V. C. Política Nacional de Assistência Técnica e Extensão Rural: Um Caminho para emancipação da agricultura familiar. In: JORNADA INTERNACIONAL DE POLÍTICAS PÚBLICAS, 7., 2015, São Luís. Políticas públicas... São Luís, MA: Universidade Federal do Maranhão, 2015. p. 1-2. Disponível em: http://www.joinpp.ufma.br/jornadas/joinpp2015/pdfs/eixo10/politica-nacional-de-assistencia-tecnicae-extensao-rural-um-caminho-para-emancipacao-da-agricultura-familiar.pdf. Acesso em: 02 de abr. 2020. 
SANTOS, R. O. et al. Extensão rural na agricultura familiar: As características de uma família agrícola no município de Santana, Amapá, Brasil. Ciência em Extensão, São Paulo, v.14, n.4, p.97 112, 2018. Disponível em: https://ojs.unesp.br/index.php/revista_proex/article/viewFile/1447/2166. Acesso em: 03 de abr. 2020.

SCHNEIDER, S. A importância da pluriatividade para as políticas públicas no Brasil. Politica Agrícola, Porto Alegre, RS, n. 3 p. 2-20, jul./ago./set. 2007. Disponível em: https://seer.sede.embrapa.br/index.php/RPA/article/viewFile/457/408\#: :text=Acredita\%2Dse\%20que $\% 2 \mathrm{C} \% 20$ por $\% 20$ meio $\% 20 \mathrm{da} \% 20$ pluriatividade $\% 2 \mathrm{C} \% 20 \mathrm{os} \% 20$ agricultores,formas $\% 20 \mathrm{de} \% 20$ acesso $\% 20 \mathrm{a} \% 20$ rendas. Acesso em: 30 de ago. 2020.

SILVA, C. DA; SIMIONI, F. J.; TALAMINI, E. Fatores determinantes da renda de famílias rurais do município de Painel - SC. Teoria e Evidencia Econômica, Paraná, v. 1, n. 32, p. 1-20, 2009. Disponível em: http://seer.upf.br/index.php/rtee/article/download/4745/3179/. Acesso em: 22 de out. 2019.

SILVA, L. C. A. et al. Diversificação rural: a importância para agricultura familiar da produção para autoconsumo na cultura do tabaco. In: Seminário Internacional Sobre Desenvolvimento Regional, 9., 2019, Santa Cruz Do Sul. IX Seminário Internacional Sobre Desenvolvimento Regional, Santa Cruz do Sul, RS: Programa de pós-graduação em desenvolvimento regional - Universidade de Santa Cruz do Sul, 2019. p. 4-18. Disponível em:

https://online.unisc.br/acadnet/anais/index.php/sidr/article/viewFile/19282/1192612725 . Acesso em: 22 de out. 2019.

SILVA, N. D. et al. Desafios do uso da água na produção de alimento no projeto de assentamento Mãe Maria no município de Alto Boa Vista - MT: uma perspectiva sobre a conscientização. Cadernos de agroecologia, Brasília, DF, v. 13, no 1, p 1-6, jul./ 2017. Disponível em: http://cadernos.abaagroecologia.or.br/index.php/cadernos/article/dowload/1637/1051/ . Acesso em: 22 de out. 2019.

SILVA, R. de O. P. e. Assistência Técnica e Extensão Rural no Brasil: um pouco de sua história. Instituto de Economia Agrícola, São Paulo, v. 11, n. 5, p. 1-6, maio 2016. Disponível em: http://www.iea.sp.gov.br/ftpiea/AIA/AIA-33-2016.pdf. Acesso em 10 de jun. 2020.

TÉCNICA. In: DICIO, Dicionário Online de Português. Porto: 7 Graus, 2020. Disponível em: https://www.dicio.com.br/trabalho/. Acesso em: 30 ago. 2020.

ZÓTIS, T. S. Causas e consequências da evasão de jovens da comunidade rural de São Vitor, município de Camargo/RS. 2011. 67 f. Trabalho de Conclusão de Curso - Tecnólogo em Planejamento e Gestão para o Desenvolvimento Rural, Universidade Federal do Rio Grande do Sul, Camargo. 